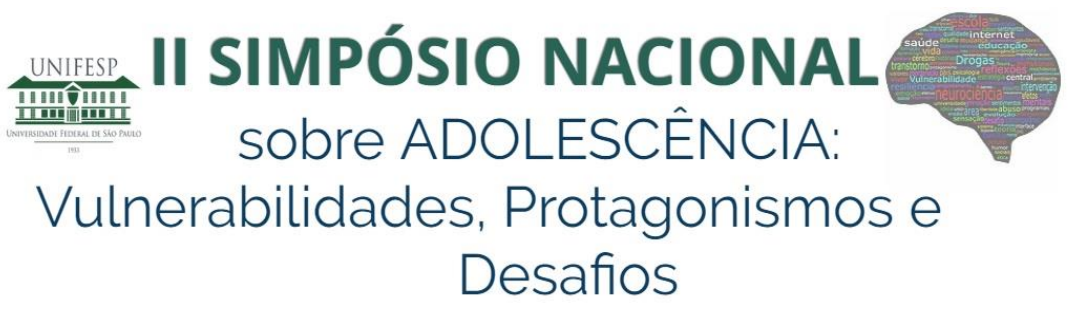

\title{
O uso de mídias digitais por estudantes de universidades públicas e particulares: um estudo exploratório
}

\author{
Adriana Scatena \\ Universidade Federal de São Paulo \\ André Luiz Monezi Andrade \\ Universidade Anhembi Morumbi \\ Universidade Federal de São Paulo \\ André Bedendo \\ Universidade Federal de São Paulo \\ Denise de Micheli \\ Universidade Federal de São Paulo
}

\section{Como citar:}

SCATENA, Adriana et al. O uso de mídias digitais por estudantes de universidades públicas e particulares: um estudo exploratório. In: II SIMPÓSIO NACIONAL SOBRE ADOLESCÊNCIA: VULNERABILIDADE, PROTAGONISMOS E DESAFIOS, 2. 2016, São Paulo. Anais...[S.I]: 2016. p. 53.

DOI: http://dx.doi.org/10.22388/2525-5894.2016.033

Introdução: o uso de mídias digitais é um fenômeno crescente na sociedade, especialmente entre os jovens. No Brasil, aproximadamente $70 \%$ desta população ainda acessa a internet principalmente por computadores, mas o acesso por celulares vem crescendo rapidamente. No ano de $2012,20 \%$ dos jovens acessavam a internet por algum dispositivo móvel, em 2013 já eram 53\%. Esta nova forma de comunicação também está relacionada com o desenvolvimento de psicopatologias, levando a um grau de sofrimento psíquico entre os jovens. Existem diversas variáveis que podem influenciar no uso destas mídias, desde fatores socioeconômicos até emocionais.

Objetivos: avaliar a prevalência e o padrão de uso de mídias digitais entre estudantes de universidades públicas e privadas.

Métodos: participaram da pesquisa 5986 estudantes a partir de um link disponibilizado na internet para o preenchimento virtual. Os estudantes preencheram o Internet Addiction Test (IAT) com o objetivo de avaliar o padrão de uso de internet, além de um questionário socioeconômico desenvolvido pelos autores composto por 8 questões gerais (gênero, estado, estado civil, idade, número de filhos, curso de graduação, semestre e tipo de universidade) e 15 questões específicas acerca sobre o padrão de uso das mídias digitais.

Resultados: os dados indicaram que a média de idade foi ligeiramente superior nos estudantes das universidades públicas e a pontuação média do IAT foi significativamente maior nos estudantes de universidades públicas $(p<0,01)$. Além disso, os estudantes das Universidades públicas passaram um tempo diário maior (em minutos) (296; DP $= \pm 232)$ em relação aos das Universidades privadas $(284 ; \mathrm{DP}= \pm 232$ ). Conclusões: os dados indicaram claramente que variáveis socioeconômicas podem influenciar no uso 
destas mídias digitais, podendo levar problemas emocionais mais graves. Neste estudo, hipotetizamos que muitos estudantes de universidades públicas podem ter um tempo ocioso ligeiramente maior, o que favorece o uso destas mídias.

Palavras-chave: Dependência de internet. Smartphones. Mídias digitais. Estudantes. 